\title{
Characterization and Bone Differentiation of Nanoporous Structure Fabricated on Ti6Al4V Alloy
}

\author{
Yingmin Su, ${ }^{1}$ Satoshi Komasa, ${ }^{1}$ Tohru Sekino, ${ }^{2}$ Hiroshi Nishizaki, ${ }^{1}$ and Joji Okazaki \\ ${ }^{1}$ Department of Removable Prosthodontics and Occlusion, Osaka Dental University, 8-1 Kuzuha-hanazono-cho, Hirakata, \\ Osaka 573-1121, Japan \\ ${ }^{2}$ The Institute of Scientific and Industrial Research, Osaka University, Mihogaoka 8-1, Ibaraki, Osaka 567-0047, Japan
}

Correspondence should be addressed to Yingmin Su; suyingmin1987@gmail.com

Received 9 September 2015; Revised 28 October 2015; Accepted 1 November 2015

Academic Editor: Bo Tan

Copyright ( 2015 Yingmin Su et al. This is an open access article distributed under the Creative Commons Attribution License, which permits unrestricted use, distribution, and reproduction in any medium, provided the original work is properly cited.

\begin{abstract}
The optimal temperature for the alkaline treatment and subsequent heat treatment is determined to optimize the nanoporous structures formed on Ti6Al4V titanium alloy plates. Surface characterization of the alkali-heat treated samples was performed by scanning electron microscopy, atomic force microscopy, X-ray photoelectron spectroscopy, and X-ray diffraction. The effects of heating temperatures on albumin adhesion, rat bone marrow mesenchymal stem cells (BMMSCs) adhesion, alkaline phosphatase activity, osteocalcin production, calcium deposition, and Runx 2 mRNA expression were evaluated. The nanotopography, surface chemistry, and surface roughness were unchanged even after heat treatments at 200,400 , and $600^{\circ} \mathrm{C}$. Only the amorphous sodium titanate phase changed, increasing with the temperature of the heat treatments, which played a crucial role in promoting superior cell adhesion on the nanoporous surface compared with the sodium hydrogen titanate obtained by a single alkali treatment. The heat treatment at $800^{\circ} \mathrm{C}$ did not enhance cell attachment on the surface because the nanostructure was dramatically destroyed with the reappearance of $\mathrm{Al}$ and $\mathrm{V}$. This study reveals that nanoporous structures with amorphous sodium titanate were fabricated on Ti6Al4V surface through an amended alkali-heat treatment process to improve BMMSCs adhesion.
\end{abstract}

\section{Introduction}

Titanium alloys are the most frequently used metallic for medical implants, due in part to the spontaneous protective oxide coating that forms on their surface, although titanium6-aluminium-4-vanadium (Ti6Al4V) alloy has been used most frequently as a biomaterial. The implants must have surface treatments in advance for a successful osseointegration. The surface characteristics of the implant material affect the rate and extent of osseointegration. Vandrovcová and Bačáková [1] recently reviewed the growing evidence demonstrating that surface-modified materials are highly effective for adhesion, growth, and osteogenic differentiation of cells.

The structures used in this study were nanostructures similar to the titanium dioxide (titania, $\mathrm{TiO}_{2}$ ) nanotubes, created by titanium deposition using the process of $\mathrm{TiO}_{2}$ sputtering, and were named titanium nanosheets (TNS) [2]. Recently, it was shown that titania nanotubes and TNS can be formed on titanium metal surfaces by treatment with $10 \mathrm{M}$ $\mathrm{NaOH}$ aqueous solution at $30^{\circ} \mathrm{C}$. It has also been shown that treatment with $\mathrm{NaOH}$ aqueous solution produces a rough, nanoscale surface. A previous study reported that TNS produced via chemical processing promoted osteogenic differentiation of rat bone marrow (RBM) cells [3-5]. The surface properties and structures of materials play important roles in the adsorption of proteins, which might influence cell behavior.

In recent study, we found TNS-modified titanium alloy surfaces induce RBM cell bone differentiation [5]. Furthermore, X-ray photoelectron spectroscopy (XPS) analysis revealed that Ti6Al4V releases its $\mathrm{Al}$ and $\mathrm{V}$ alloy species during $\mathrm{NaOH}$ treatment; so $\mathrm{Al}$ and $\mathrm{V}$ are undetected on the modified surface of treated alloy disks, whereas the contents of $\mathrm{Ti}, \mathrm{Na}$, and $\mathrm{O}$ are barely affected by alkali treatment $[5,6]$. Our previous research also reports that $\mathrm{NaOH}$ treatment leads to the formation of a Ti-O-Na titanate layer on the $\mathrm{Ti}$ 
surface $[4,7] . \mathrm{V}$ is known to exhibit biological toxicity, so it is interesting that this component was undetected on the TNS-modified titanium surface. However, this TNS hydrogel layer is so brittle that it easily detaches from the implant and can cause many problems, including degradation in the living body due to inhomogeneous composition distribution.

Recently, methods for inducing bioactivity for direct bonding between the bone and implant by means of chemical surface modification of the biomaterial have been widely studied. Kim et al. introduced combined alkali- with heattreatment as a method of surface modification of titanium alloys to improve bioactivity [8]. However, some researchers report that a stable sodium titanate hydrogel layer is fabricated on the titanium surface during heat treatment after alkali treatment [8-11]. The heat treatment subsequent to the alkali treatment appears to be indispensable. Several in vivo studies have shown that alkali-heat treated $\mathrm{Ti}$ and Ti6Al4V alloy can bond directly to bone with a high bonding strength, whereas fibers attached on the implant surface show a lack of bone-bonding ability after a single alkali treatment [12-14].

The aims of the present study were to investigate the combination of alkali treatment with various heat treatments of the Ti6Al4V alloy and evaluate the ability of the modified surface to affect the morphology, osteogenic differentiation, and biocompatibility of RBM cells to increase the success rate of titanium implants. The null hypothesis was that there would be no difference in cellular behavior on titanium surfaces as a result of different heat treatment at several temperatures after $\mathrm{NaOH}$ treatment.

\section{Materials and Methods}

2.1. Sputtering Procedure. Ti6Al4V disks (15 $\mathrm{mm}$ in diameter and $1 \mathrm{~mm}$ in thickness) of Ti grade 5 (chemical composition in wt.\% N: 0.02; C: 0.03; H: 0.011; Fe: 0.22; O: 0.16; Al: 6.12; V: 3.93; and Ti: balance) were prepared as the substrate material (Daido Steel, Osaka, Japan). Nanoporous Ti6Al4V alloy was produced by treatment with concentrated alkali solution at room temperature, as published earlier. In short, the alloy disks were successively polished with $\mathrm{SiC}$ abrasive paper $(600,800,1000$, and 1500 grits), ultrasonically rinsed in acetone, ethanol, and distilled water for $10 \mathrm{~min}$ each, and dried in air. The disks were soaked in $10 \mathrm{M} \mathrm{NaOH}$ solution at $30^{\circ} \mathrm{C}$ for $24 \mathrm{~h}$, washed with distilled water, and dried at room temperature overnight to obtain the nanostructured alloy samples. Following the alkaline treatment at $30^{\circ} \mathrm{C}$, the samples were heated to $200,400,600$, and $800^{\circ} \mathrm{C}$ at a rate of $5^{\circ} \mathrm{C} / \mathrm{min}$ in an electrical furnace, maintained at the desired temperature for $1 \mathrm{~h}$, and cooled naturally to room temperature. An alloy subjected to only $\mathrm{NaOH}$ treatment was used as a control sample.

2.2. Surface Analysis. The surface characterization of the alkali-heat treated samples was observed by scanning electron microscopy (SEM) (S-4800; Hitachi, Tokyo, Japan) with an acceleration voltage of $10 \mathrm{kV}$.

Atomic force microscopy (AFM) (SPM-9600; Shimadzu Tokyo, Japan) was also performed to obtain the mean average surface roughness $\left(R_{a}\right)$, mean peak-to-valley height $\left(R_{z}\right)$, and the two-dimensional surface topography. The surface chemical composition was examined by X-ray photoelectron spectrometry (XPS) (PHI X-tool; ULVAC-PHI, Kanagawa, Japan). The thickness of the modified layer was also determined by XPS and Ar-etching [13]. The surface phase was investigated by X-ray powder diffraction (XRD) (XRD-6100; Shimadzu Tokyo, Japan). Spectra were recorded at $2 \theta$ from $20^{\circ}$ to $60^{\circ}$ with CuKa radiation source operating at $40 \mathrm{kV}$ and $200 \mathrm{~mA}$ and a scanning rate of $2 \% \mathrm{~min}$ and an incident angle of $1^{\circ}$.

2.3. Protein Adsorption Assay. Bovine serum albumin (BSA), fraction V (Pierce Biotechnology), was used as a model protein. Protein solution $(300 \mu \mathrm{L}, 1 \mathrm{mg} / \mathrm{mL}$ protein in a saline solution) was pipetted into each sample. After incubation for $1,3,6$, or $24 \mathrm{~h}$ at $37^{\circ} \mathrm{C}$, nonadherent proteins were removed and mixed with bicinchoninic acid (Pierce Biotechnology) at $37^{\circ} \mathrm{C}$ for $1 \mathrm{~h}$. The amount of removed albumin and the total amount of albumin inoculated were quantified using a microplate reader at $562 \mathrm{~nm}$. The rate of albumin adsorption was calculated as the percentage of albumin adsorbed on samples relative to the total amount of albumin in solution.

2.4. Cell Culture. Rat BMMSCs were isolated and cultured according to our previously published procedures [12]. The rat BMMSCs were obtained from the femurs of 8-weekold Sprague Dawley rats. This experiment was approved by the Guidelines for Animal Experimentation of Osaka Dental University (approval number 14-03013). Primary cells were cultured at $37^{\circ} \mathrm{C}$ in a $5 \% \mathrm{CO}_{2}$ atmosphere in a growth medium containing minimal essential medium (Nacalai Tesque, Inc., Tokyo, Japan) supplemented with $10 \%$ fetal bovine serum (FBS; Nacalai Tesque, Inc.) and antibiotic-antimycotic mixed stock solution (Nacalai Tesque, Inc.). The culture medium was changed every 3 days.

2.5. Cell Proliferation. Rat BMMSCs were seeded on the specimens at an initial density of $4 \times 10^{4} \mathrm{cells} / \mathrm{cm}^{2}$, and cell attachment was analyzed after $72 \mathrm{~h}$ and $7 \mathrm{~d}$. The nonadherent cells were removed by washing with phosphate-buffered saline (PBS) after the appropriate incubation time. CellTiterBlue Reagent $(50 \mu \mathrm{L})$ and PBS $(250 \mu \mathrm{L})$ were then added to each well. The cell numbers were measured under CellTiterBlue Cell Viability Assay (Promega, Madison, WI, USA) according to the manufacturer's protocol.

2.6. Alkaline Phosphatase Activity. After 7 and 14 days of culture, cells were washed with PBS, lysed with $200 \mu \mathrm{L}$ of $0.2 \%$ Triton X-100 (Sigma, St. Louis, MO, USA) and the lysate was transferred to a microcentrifuge tube containing a $5 \mathrm{~mm}$ hardened steel ball. Tubes were agitated on a shaker (Mixer Mill Type MM 301, Retsch GmbH, Haan, Germany) at $29 \mathrm{~Hz}$ for $20 \mathrm{~s}$ to homogenize the samples. Alkaline phosphatase (ALP) activity was measured using an Alkaline Phosphatase Luminometric ELISA Kit (Sigma) according to the manufacturer's protocol. The reaction was terminated with $3 \mathrm{~N}$ $\mathrm{NaOH}$ to a final concentration of $0.5 \mathrm{~N} \mathrm{NaOH}$ and pnitrophenol production was measured by absorbance at $405 \mathrm{~nm}$ using a 96-well microplate reader (SpectraMax M5, 
Molecular Device, Inc., Sunnyvale, CA, USA). DNA content was measured using the PicoGreen dsDNA Assay Kit (Invitrogen) according to the manufacturer's protocol. To normalize ALP activity, the amount of ALP was normalized to the amount of DNA in the cell lysate.

2.7. Osteocalcin ELISA Analysis. The sandwich enzyme immunoassay used in this study was specific for rat osteocalcin (OCN) and can measure its levels directly in cell culture supernatant after 21 and 28 days of culture. The OCN levels in cell culture supernatant were measured using a commercially available ELISA Kit (Rat Osteocalcin ELISA Kit DS, DS Pharma Biomedical Co., Ltd., Osaka, Japan) according to the manufacturer's instructions.

2.8. Mineralization. Calcium deposited in the extracellular matrix was measured after dissolution with $10 \%$ formic acid. The amount of calcium was quantified using a Calcium ETest Kit (Wako Pure Chemical Industrials Ltd.). After 21 and 28 days of culture, $1 \mathrm{~mL}$ Calcium E-Test reagent and $2 \mathrm{~mL}$ kit buffer were added to $50 \mu \mathrm{L}$ of collected medium, and the absorbance of the reaction products was measured at $610 \mathrm{~nm}$ using a 96-well microplate reader (SpectraMax M5). The concentration of calcium ions was calculated from the absorbance value relative to a standard curve.

2.9. Real-Time PCR Analysis. After 3 days of culture, the total RNA was extracted from the cells and cDNA was synthesized from $1 \mu \mathrm{g}$ of RNA using a High Capacity cDNA Archive Kit (Applied Biosystems Inc., Foster City, CA, USA). Runx-2 mRNA expression was investigated by real-time reverse transcriptase-polymerase chain reaction (RT-PCR) using a StepOne Plus Real-Time RT-PCR System (Applied Biosystems). In a fast 96 -well reaction plate $(0.1 \mathrm{~mL}$ well volume; Applied Biosystems), $10 \mu \mathrm{L}$ of Taqman Fast Universal PCR Master Mix, $1 \mu \mathrm{L}$ of Runx2 primer (Taqman Gene Expression Assays), $2 \mu \mathrm{L}$ of sample cDNA, and $7 \mu \mathrm{L}$ of diethylpyrocarbonate (DEPC) water (Nippongene) were added to each well. The plate was subjected to 40 reaction cycles of $95^{\circ} \mathrm{C}$ for $1 \mathrm{~s}$ and $60^{\circ} \mathrm{C}$ for $20 \mathrm{~s}$. The reactive gene expression rate was calculated employing the $\Delta \Delta \mathrm{Ct}$ method [11] in each group assuming the gene expression rate of the negative control group.

2.10. Statistical Analysis. Statistical analysis was performed by one-way analysis of variance followed by Turkey's test. All results were based on a mean \pm standard deviation from five random fields of each sample. Differences were considered statistical at $P<0.05$.

\section{Results}

3.1. Surface Morphology. The alkali treatment with $10 \mathrm{M}$ $\mathrm{NaOH}$ at $30^{\circ} \mathrm{C}$ created a nanoporous network structure on Ti6Al4V alloy surfaces. Observation of the porous network structure at the nanoscale showed that the pores were well interconnected with an average diameter of about 50 to $100 \mathrm{~nm}$ at $30^{\circ} \mathrm{C}$. Figure 1 shows SEM images of the surfaces of the $\mathrm{NaOH}$-treated alloy that were subsequently subjected to
TABLE 1: Surface roughness of the specimens subjected to alkali treatment (A30) and alkali-heat (AH) treatments under various subsequent heating temperatures.

\begin{tabular}{lcc}
\hline & $R_{a}(\mathrm{~nm})$ & $R_{z}(\mathrm{~nm})$ \\
\hline A30 & 26.581 & 291.280 \\
AH200 & 23.412 & 288.217 \\
AH400 & 25.635 & 340.186 \\
AH600 & 25.444 & 272.379 \\
AH800 & 165.384 & 372.140 \\
\hline
\end{tabular}

TABLE 2: Surface chemical compositions of the specimens subjected to alkali treatment $(\mathrm{A} 30)$ and alkali-heat $(\mathrm{AH})$ treatments under various subsequent heating temperatures.

\begin{tabular}{lccccc}
\hline \multirow{2}{*}{ Treatment } & \multicolumn{5}{c}{ Chemical composition (at\%) } \\
& $\mathrm{O}$ & $\mathrm{Na}$ & $\mathrm{Al}$ & $\mathrm{Ti}$ & $\mathrm{V}$ \\
\hline A30 & 66.39 & 5.15 & 0 & 28.46 & 0 \\
AH200 & 66.68 & 5.08 & 0 & 28.24 & 0 \\
AH400 & 67.03 & 4.89 & 0 & 27.93 & 0 \\
AH600 & 67.18 & 4.97 & 0 & 27.65 & 0 \\
AH800 & 70.23 & 0.12 & 14.62 & 10.20 & 4.83 \\
\hline
\end{tabular}

heat treatments at various temperatures. There was no evident variation of the nanoporous structure on thermally oxidized Ti6Al4V alloy surfaces after heat treatments at 200, 400, or $600^{\circ} \mathrm{C}$, but the nanoporous structure got damaged at $800^{\circ} \mathrm{C}$.

The maintenance of the nanostructure on the Ti6Al4V alloy after heat treatment over the $200-600^{\circ} \mathrm{C}$ range was also verified by AFM (Figure 1). The nanoporous network showed numerous sharp conical protrusions bordering depression areas and changed into a prismatic layer with crystals after treatment at $800^{\circ} \mathrm{C}$. The analysis of the change in the surface roughness is summarized in Table 1 . There was no obvious change in the surface roughness $\left(R_{a}, R_{z}\right)$ before and after heat treatments at $200-600^{\circ} \mathrm{C}$, but it sharply increased at $800^{\circ} \mathrm{C}$.

3.2. Surface Chemical Analysis. The broad-range XPS surface chemical analysis of the alkali-heat treated Ti6Al4V alloys is shown in Figure 2. There were no significant differences in the XPS spectrum of the specimens before and after heat treatments at $200-600^{\circ} \mathrm{C}$, but the $\mathrm{Al}$ and $\mathrm{V}$ peaks appeared after treatment at $800^{\circ} \mathrm{C}$. The surface chemical composition of the treated specimens is shown in Table 2 . No $\mathrm{V}$ and $\mathrm{Al}$ were observed, and the relative atom concentrations of the modified surfaces remained more or less unchanged before and after heat treatments at $200-600^{\circ} \mathrm{C}$. As the temperature increased to $800^{\circ} \mathrm{C}, \mathrm{V}$ and $\mathrm{Al}$ appeared, and, furthermore, the $\mathrm{Al}$ content was higher than Ti content.

3.3. XRD Phase Identification. The crystallographic structures (Figure 3 ) of the modified surfaces were assessed by XRD before and after heat treatment to demonstrate the transformation of the phases depending on the temperature of the heat treatment. The broad diffraction peaks detected at $23-29^{\circ}$ and $53^{\circ}$ were attributed to the sodium hydrogen titanate, which was the predominant composition of 

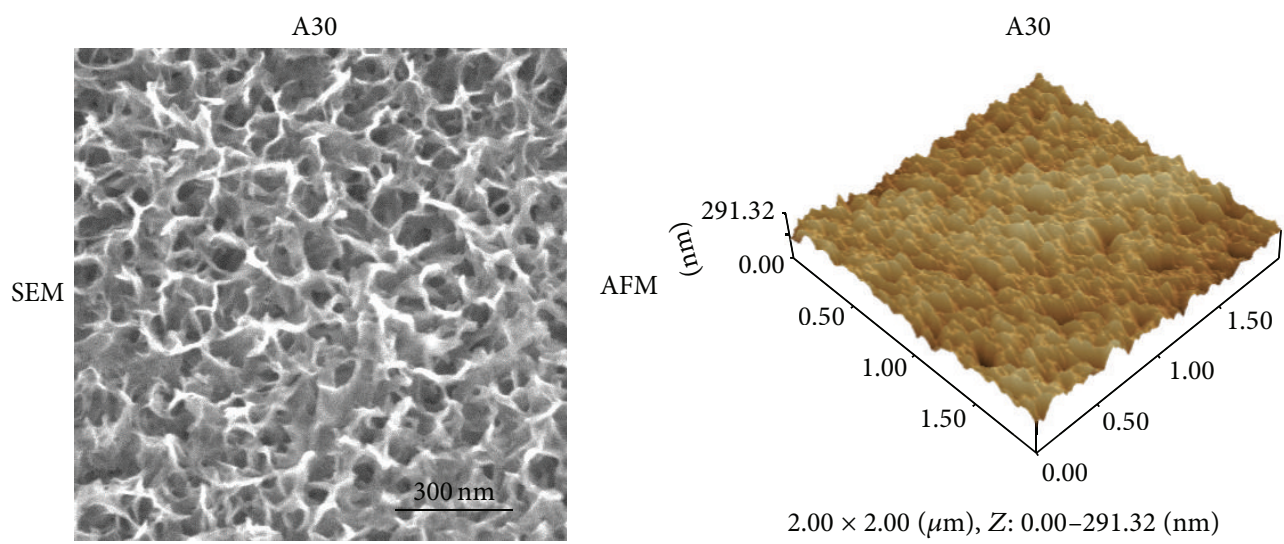

$2.00 \times 2.00(\mu \mathrm{m}), Z: 0.00-291.32(\mathrm{~nm})$
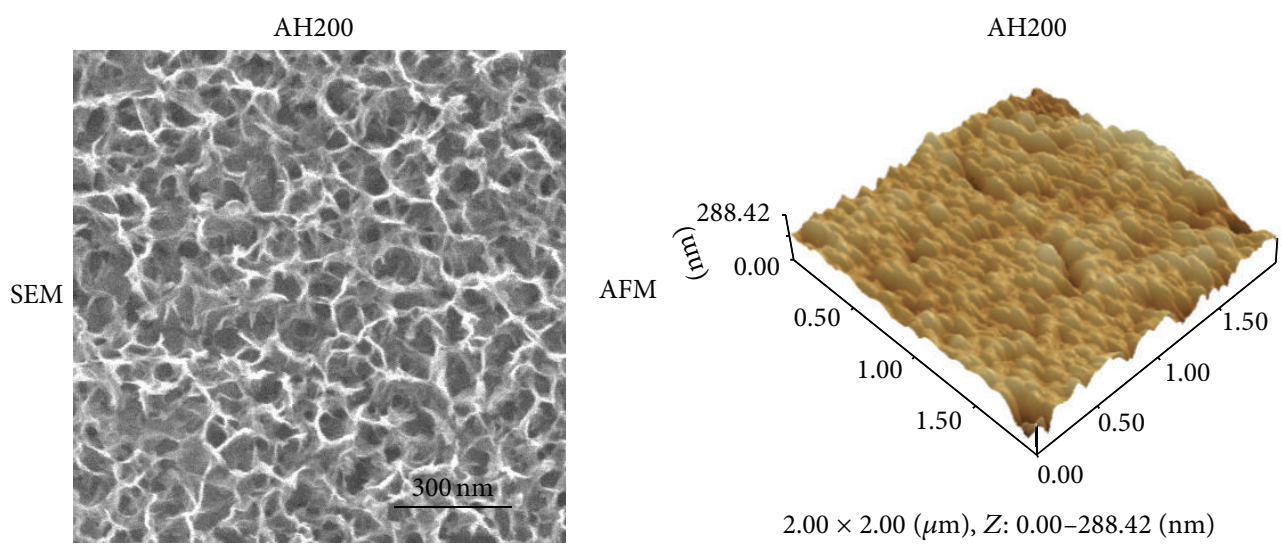

$2.00 \times 2.00(\mu \mathrm{m}), Z: 0.00-288.42(\mathrm{~nm})$
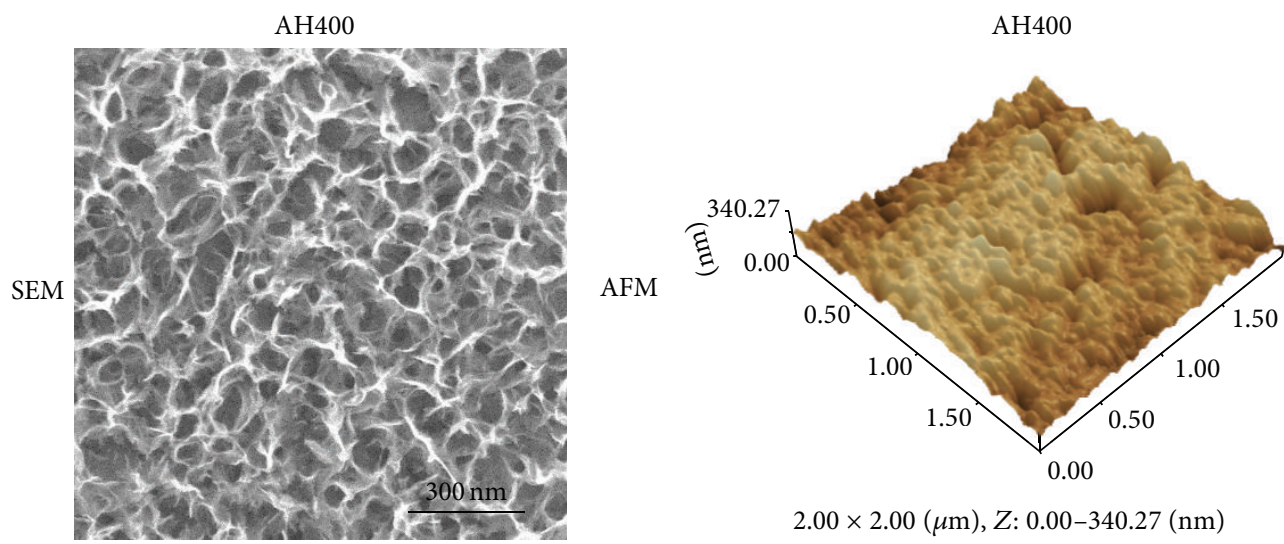

$2.00 \times 2.00(\mu \mathrm{m}), Z: 0.00-340.27(\mathrm{~nm})$
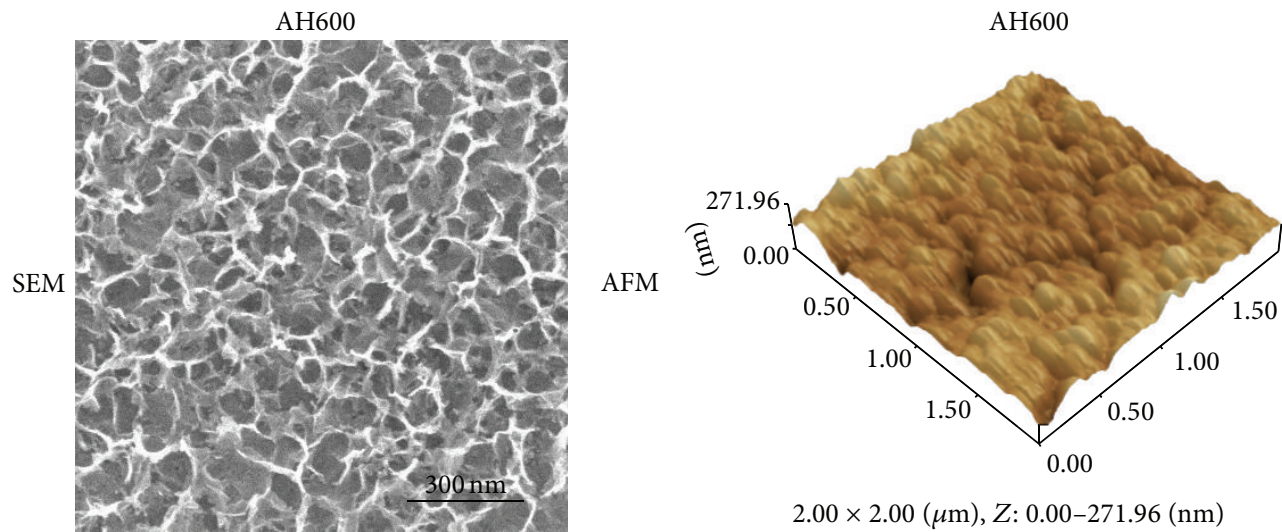

$2.00 \times 2.00(\mu \mathrm{m}), Z: 0.00-271.96(\mathrm{~nm})$ 600

Figure 1: Continued. 

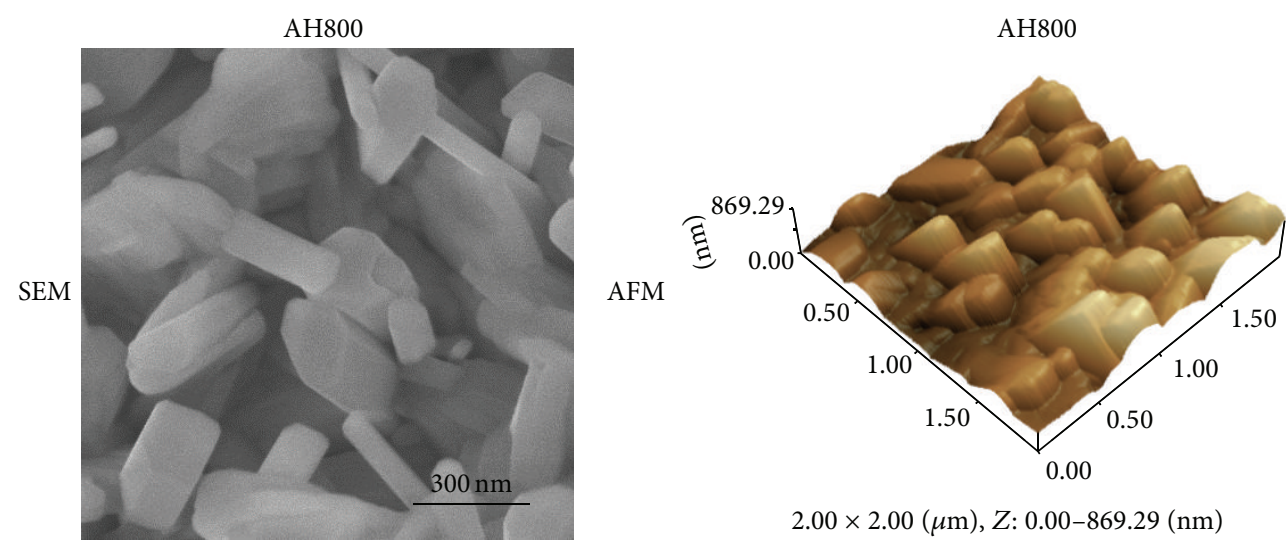

$2.00 \times 2.00(\mu \mathrm{m}), Z: 0.00-869.29(\mathrm{~nm})$

FIGURE 1: SEM and AFM photographs of the specimens subjected to alkali treatment (A30) with $10 \mathrm{M} \mathrm{NaOH}$ solution and alkali-heat treatment (AH) performed various heating temperatures at $200^{\circ} \mathrm{C}, 400^{\circ} \mathrm{C}, 600^{\circ} \mathrm{C}$, and $800^{\circ} \mathrm{C}$.

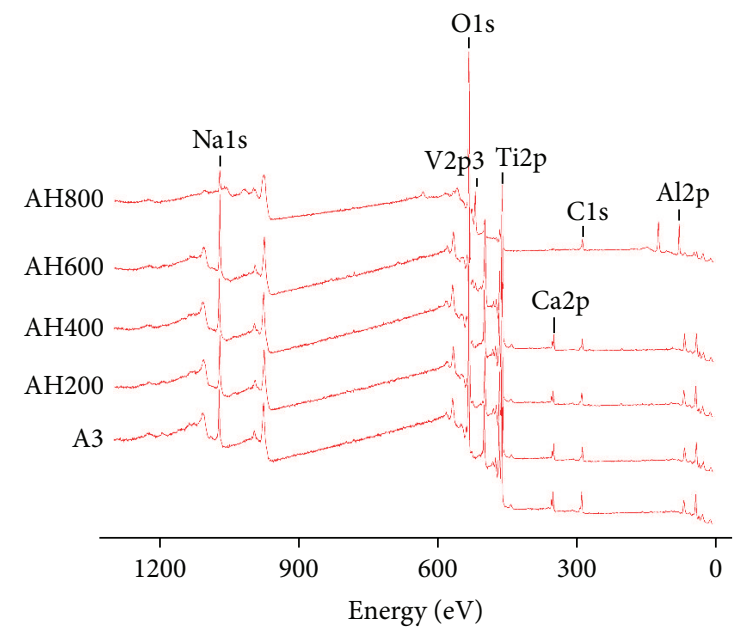

FIGURE 2: XPS survey spectra of Ti-6Al-4V alloy specimens subjected to alkali treatment $(\mathrm{A} 30)$ and alkali-heat $(\mathrm{AH})$ treatments with the subsequent heating temperatures at $200^{\circ} \mathrm{C}, 400^{\circ} \mathrm{C}, 600^{\circ} \mathrm{C}$, and $800^{\circ} \mathrm{C}$.

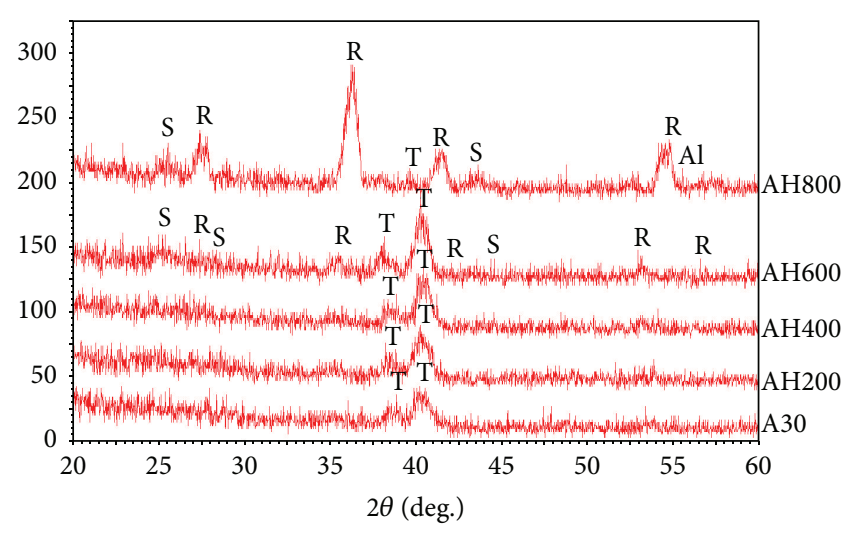

$$
\begin{array}{ll}
\text { T: titanium } & \text { R: rutile } \\
\text { S: sodium titanate } & \text { Al: aluminum oxide }
\end{array}
$$

FIGURE 3: TF-XRD pattern of the surfaces subjected to alkali treatment $(\mathrm{A} 30)$ and alkali-heat $(\mathrm{AH})$ treatments with the subsequent heating temperatures at $200^{\circ} \mathrm{C}, 400^{\circ} \mathrm{C}, 600^{\circ} \mathrm{C}$, and $800^{\circ} \mathrm{C}$. the nanoporous network after alkali treatments. The intensity of these broad peaks increased because the sodium hydrogen titanate was gradually converted into amorphous sodium titanate as the heating temperatures increased from 200 to $400^{\circ} \mathrm{C}$ and then completely transformed as the temperature increased to $600^{\circ} \mathrm{C}$, finally turning into a crystalline phase at $800^{\circ} \mathrm{C}$. Furthermore, sharp and narrow peaks newly appeared at $800^{\circ} \mathrm{C}$, which represented rutile $\left(\mathrm{TiO}_{2}\right)$, compared with the broad peaks identified as anatase $\left(\mathrm{TiO}_{2}\right)$ resulting from treatment at lower temperatures $\left(200-600^{\circ} \mathrm{C}\right)$. Peaks of the alloy element oxides $\left(\mathrm{Al}_{2} \mathrm{O}_{3}\right.$ and $\left.\mathrm{V}_{2} \mathrm{O}_{5}\right)$ were also observed in the samples heated at $800^{\circ} \mathrm{C}$.

3.4. Protein Adsorption. The amount of protein adsorbed from bovine serum albumin on the surface after $1,3,6$, and $24 \mathrm{~h}$ incubation was assayed (Figure 4). More protein was adsorbed onto the alkali-heat treated specimens than the control specimens, which increased with the alkali concentrations, except $600^{\circ} \mathrm{C}$.

3.5. Cell Proliferation Assay. Figure 5 shows the cell adhesion results. Cell proliferation on the alkali-treated samples was significantly lower $(P<0.05)$ than that observed on alkaliheat treated samples at 200,400 , and $600^{\circ} \mathrm{C}$. The adherent cell numbers gradually increased as the temperatures of the heat treatment increased over the range of $200-600^{\circ} \mathrm{C}$ but decreased on the sample subjected to heat treatment at $800^{\circ} \mathrm{C}$.

3.6. ALP Activity. ALP activity on the surface after 7 and 14 days of incubation was assayed (Figure 6). More ALP activity was adsorbed on the surface of alkali-heat treated specimens than on the control specimens. The ALP activity increased with the alkali concentrations, except $600^{\circ} \mathrm{C}$.

3.7. Osteocalcin ELIZA Analysis. The presence of osteocalcin in the supernatant of the specimens after 3 and 4 weeks of culture is shown in Figure 7. Osteocalcin production was adsorbed onto the alkali-treated specimens compared to the control specimens, which increased with the alkali concentrations, except $600^{\circ} \mathrm{C}$. 

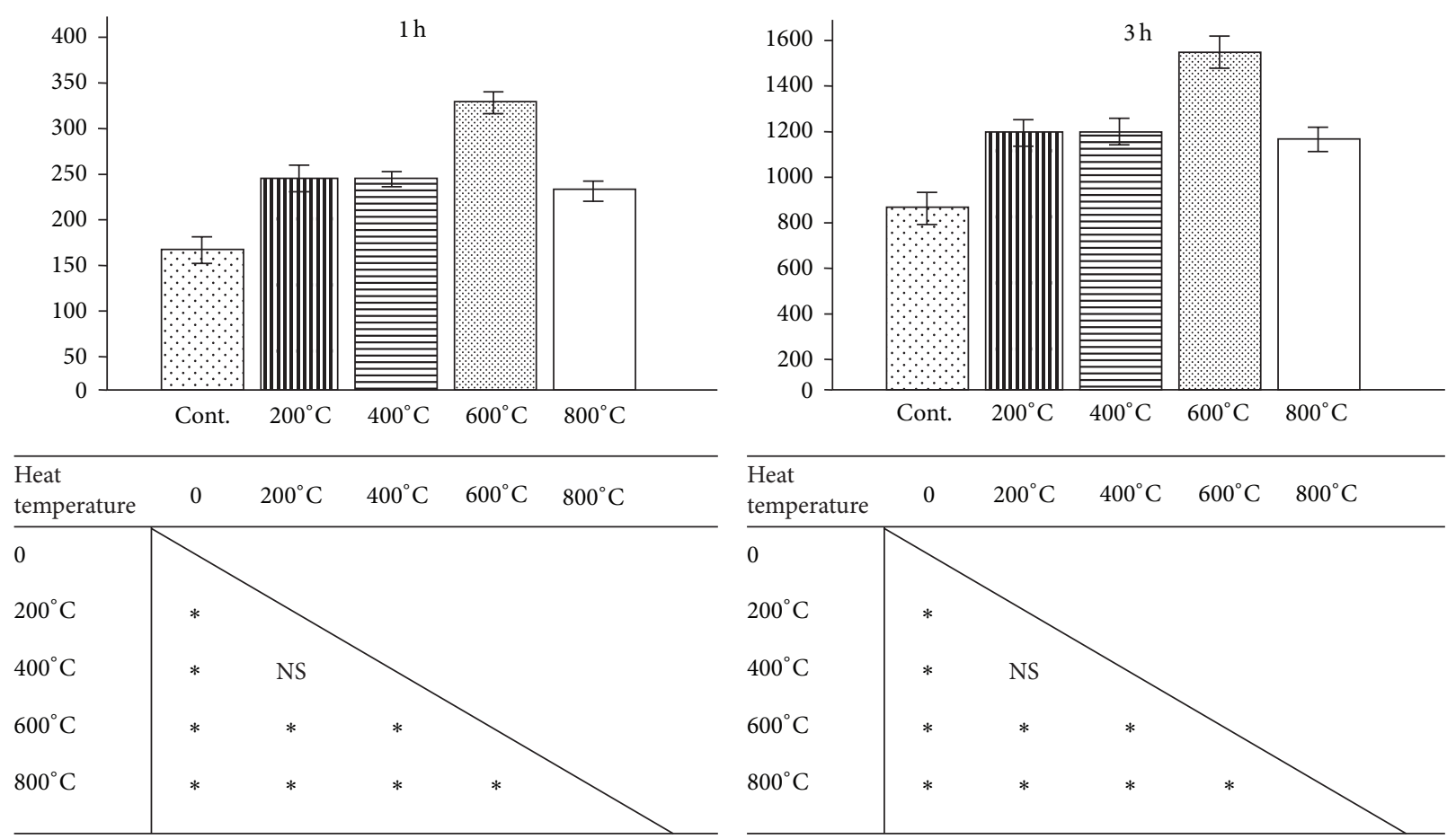

${ }^{*} P<0.05$, NS: not significant

${ }^{*} P<0.05$, NS: not significant
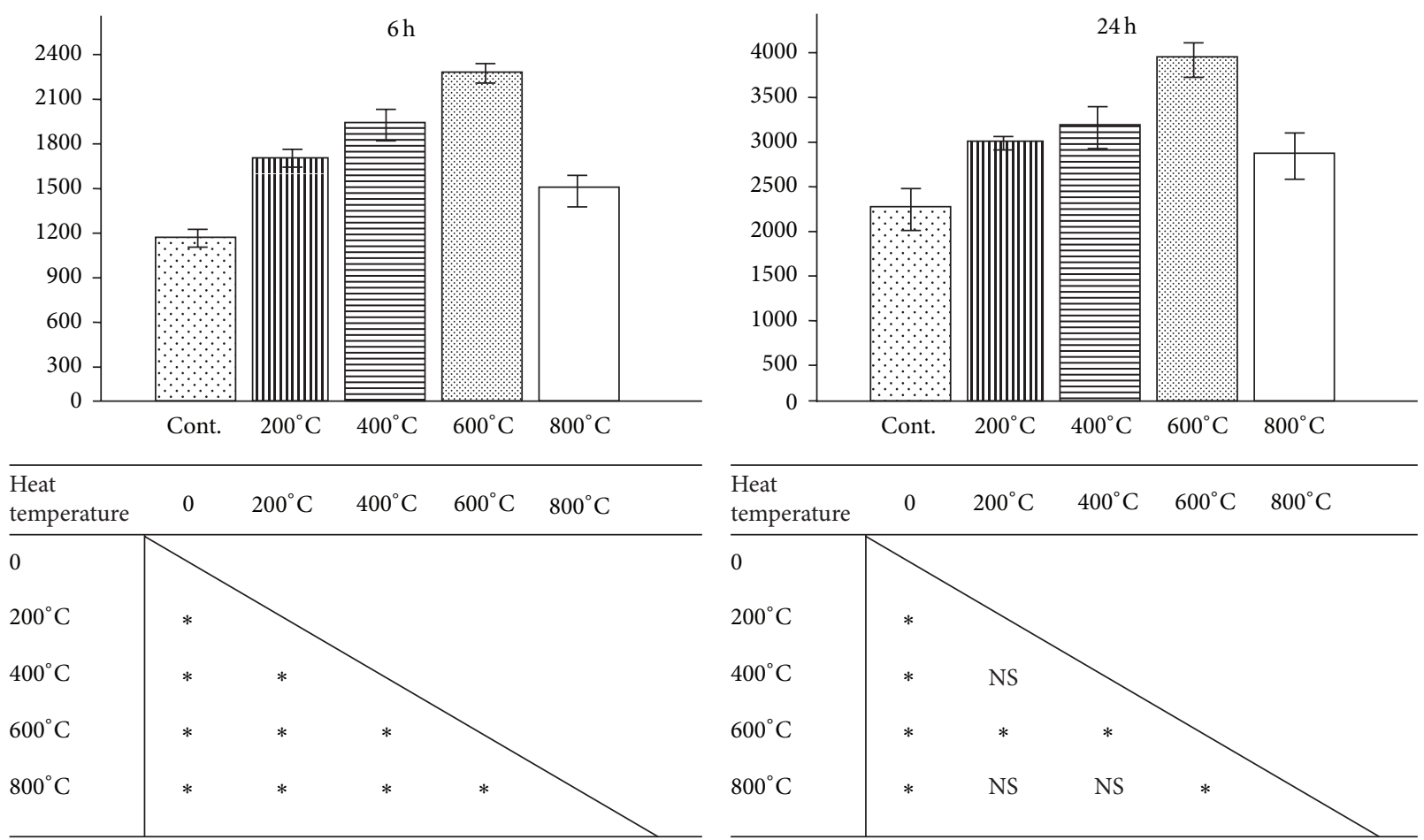

${ }^{*} P<0.05$, NS: not significant

${ }^{*} P<0.05$, NS: not significant

Figure 4: Initial number of albumin on the surfaces of Ti6Al4V specimens subjected to alkali treatment (A30) and alkali-heat (AH) treatments with the subsequent heating temperatures at $200^{\circ} \mathrm{C}, 400^{\circ} \mathrm{C}, 600^{\circ} \mathrm{C}$, and $800^{\circ} \mathrm{C}$. 


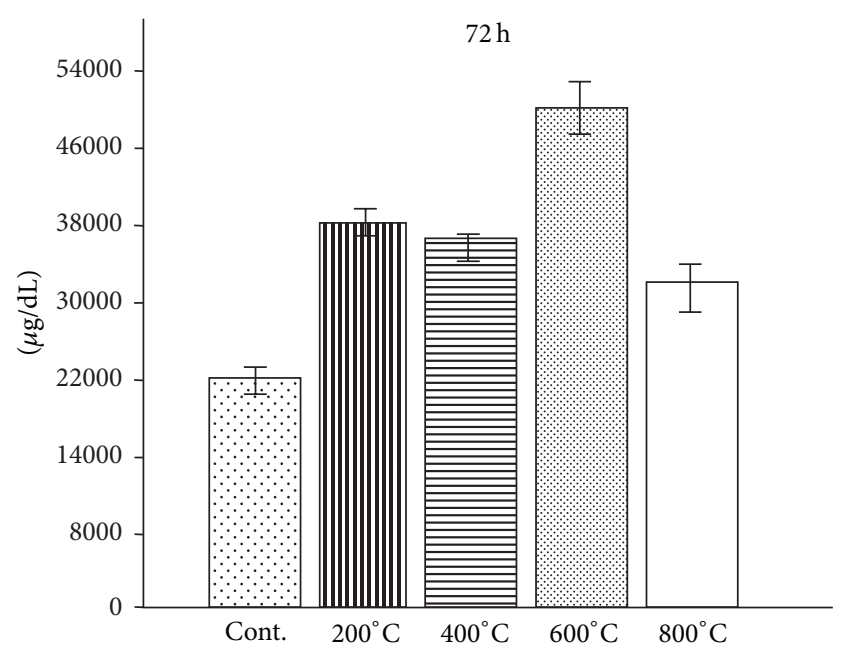

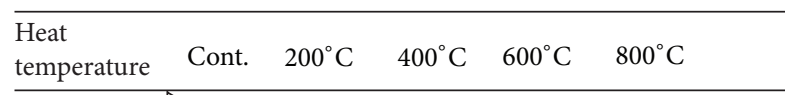

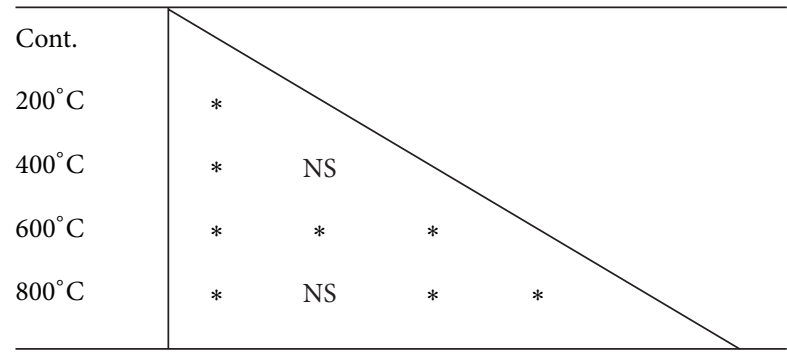

${ }^{*} P<0.05$, NS: not significant

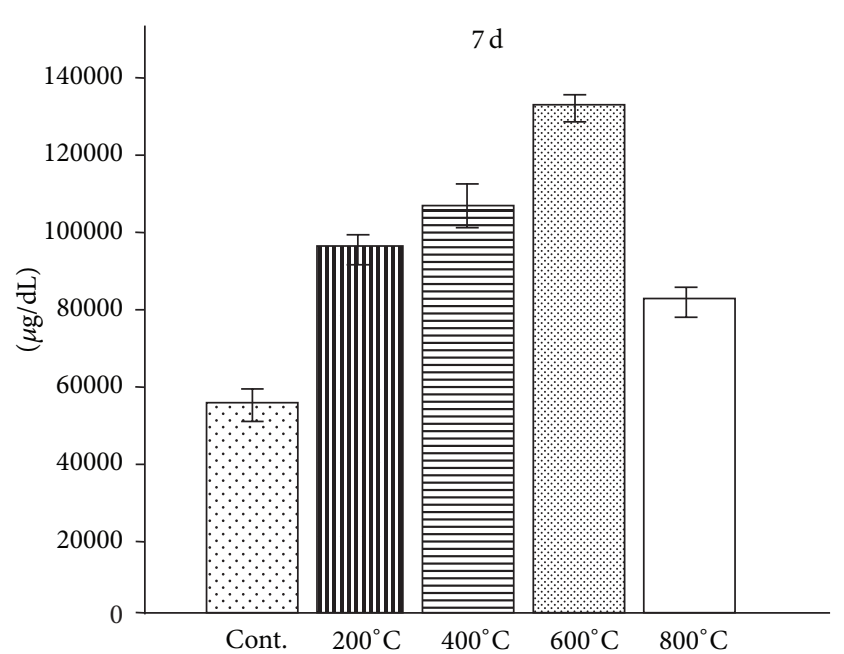

\begin{tabular}{|c|c|c|c|c|c|}
\hline $\begin{array}{l}\text { Heat } \\
\text { temperature }\end{array}$ & Cont. & $200^{\circ} \mathrm{C}$ & $400^{\circ} \mathrm{C}$ & $600^{\circ} \mathrm{C}$ & $800^{\circ} \mathrm{C}$ \\
\hline
\end{tabular}

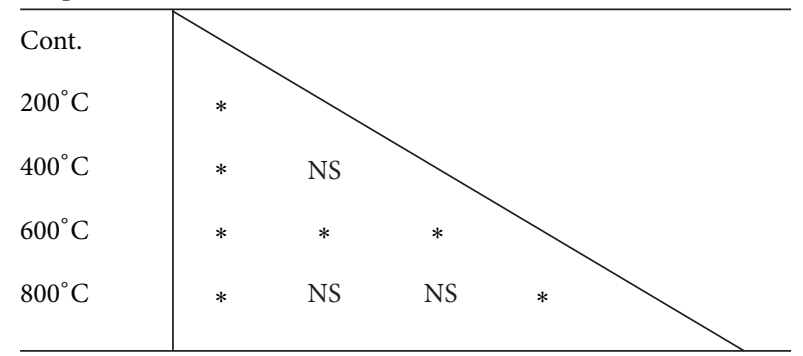

${ }^{*} P<0.05$, NS: not significant

FIGURE 5: Number of adherent BMMSCs on the surfaces of Ti6Al4V specimens subjected to alkali treatment (A30) and alkali-heat (AH) treatments with the subsequent heating temperatures at $200^{\circ} \mathrm{C}, 400^{\circ} \mathrm{C}, 600^{\circ} \mathrm{C}$, and $800^{\circ} \mathrm{C}$.

3.8. Mineralization. Calcium deposition in the supernatant of the specimens after 3 and 4 weeks of culture is shown in Figure 8. Calcium deposition was adsorbed onto the alkalitreated specimens compared to the control specimens, which increased with the alkali concentrations, except $600^{\circ} \mathrm{C}$.

3.9. Run $x 2$ mRNA Expression. Run $x 2$ is a transcription factor involved in the early stages of osteogenic differentiation. As shown in Figure 9, Runx2 activity was adsorbed onto the alkali-treated specimens compared to the control specimens, which increased with the alkali concentrations, except $600^{\circ} \mathrm{C}$.

\section{Discussion}

This study investigated whether RBM cells respond differently to titanium alloy implants with chemical and heat treatment surface modifications compared with those that were untreated. The results of this study showed that, after the proliferation of cells, expressions of Runx 2 transcription factor and RBM cell differentiation markers, such as ALP and OCN, were elevated in alkali- and heat-treated alloy disks compared with alkali modified titanium alloy disks.
This study found that calcium deposition in the extracellular matrix of the RBM cells was increased in the presence of surface-treated titanium alloy disks compared with controls disks. Our results suggest that titanium alloy disks modified by alkali and heat treatment at $600^{\circ} \mathrm{C}$ promote $\mathrm{RBM}$ cell proliferation, differentiation, and activation, which augment calcium deposition.

Alkali- and heat-treated titanium alloy was reported to bond to bone so it is thought to be clinically applicable as an implant and orthopedic material. In theory, if alkali treatment without heat treatment could induce the bone-bonding ability with titanium alloy, it would be possible to prepare bioactive titanium alloy implants using $\mathrm{NaOH}$ solution. Kim et al. $[8,13]$ reported that alkali-treated titanium without heat treatment has the ability to form apatite on its surface in simulated body fluid (SBF) similar to combined alkaliand heat-treated titanium. However, this layer is so unstable; it loses its apatite-forming ability during preservation or following implantation, although it is not known at which stage this apatite-forming ability is lost. Many in vitro studies have shown that adhesive tape detaches from the surface layer of alkali-treated titanium and titanium alloy from its 

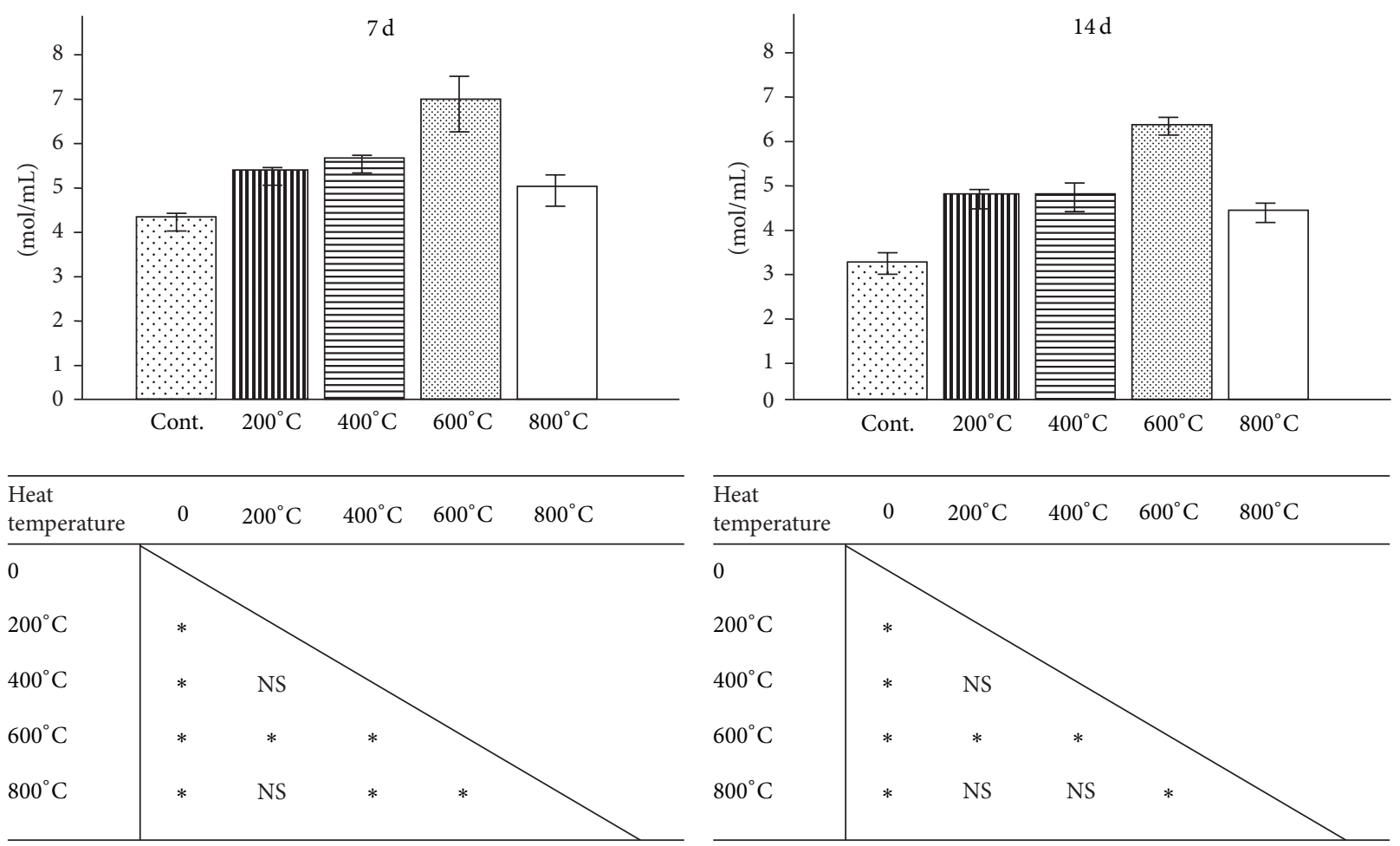

${ }^{*} P<0.05$, NS: not significant

${ }^{*} P<0.05$, NS: not significant

FIGURE 6: ALP activity on the surfaces of Ti6Al4V specimens subjected to alkali treatment (A30) and alkali-heat (AH) treatments with the subsequent heating temperatures at $200^{\circ} \mathrm{C}, 400^{\circ} \mathrm{C}, 600^{\circ} \mathrm{C}$, and $800^{\circ} \mathrm{C}$.
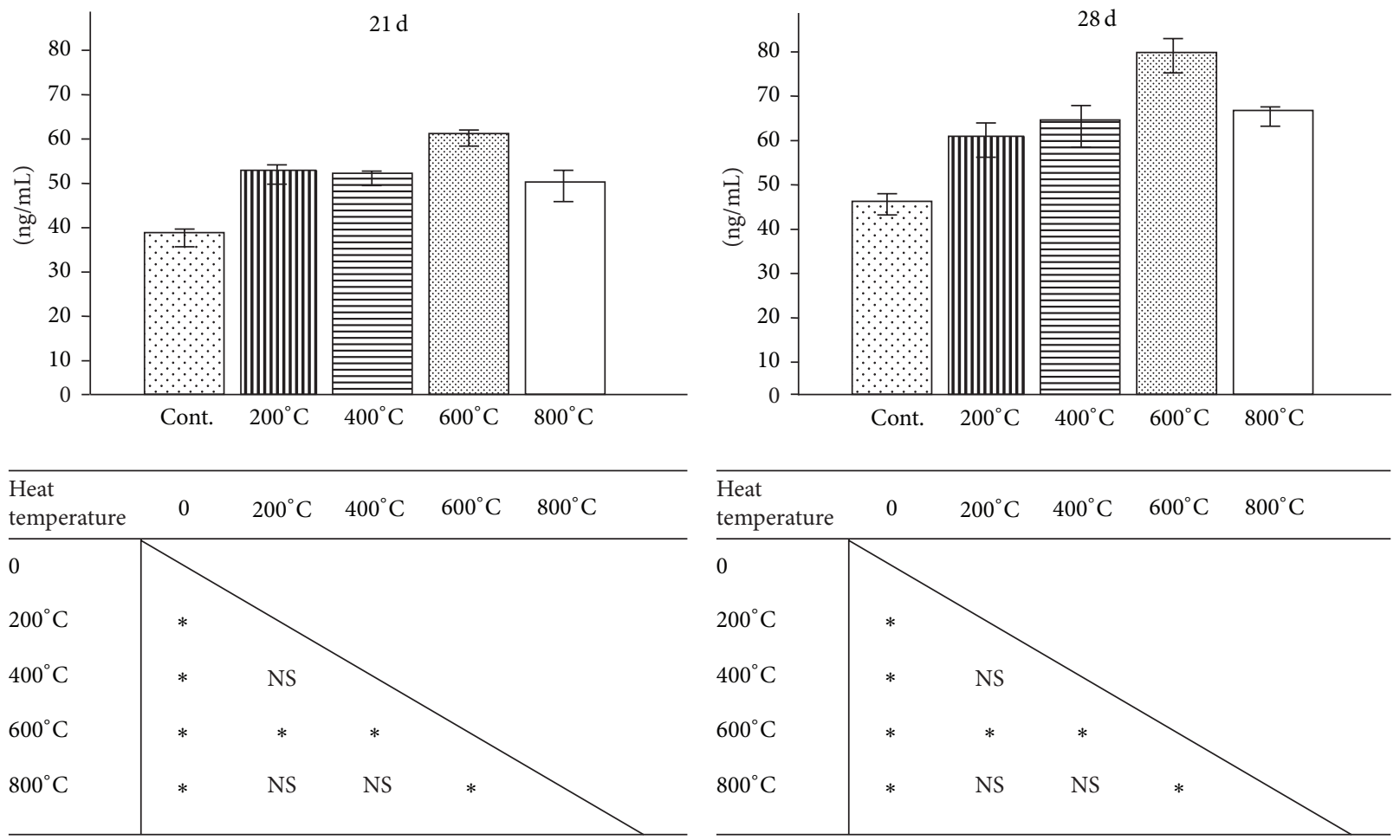

${ }^{*} P<0.05$, NS: not significant

${ }^{*} P<0.05$, NS: not significant

Figure 7: OCN production on the surfaces of Ti6Al4V specimens subjected to alkali treatment (A30) and alkali-heat (AH) treatments with the subsequent heating temperatures at $200^{\circ} \mathrm{C}, 400^{\circ} \mathrm{C}, 600^{\circ} \mathrm{C}$, and $800^{\circ} \mathrm{C}$. 

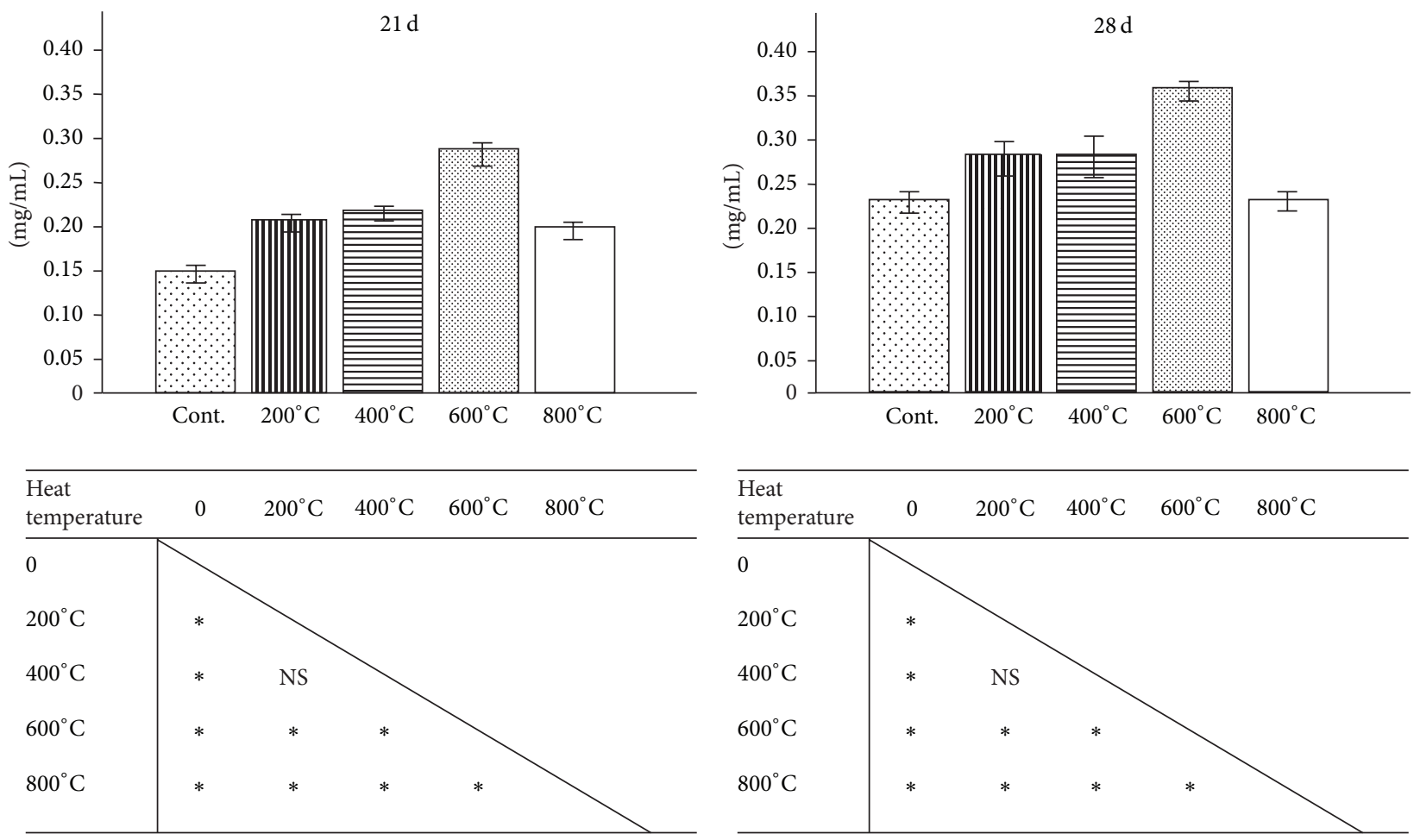

${ }^{*} P<0.05$, NS: not significant

${ }^{*} P<0.05$, NS: not significant

Figure 8: Calcium deposition on the surfaces of Ti6Al4V specimens subjected to alkali treatment (A30) and alkali-heat (AH) treatments with the subsequent heating temperatures at $200^{\circ} \mathrm{C}, 400^{\circ} \mathrm{C}, 600^{\circ} \mathrm{C}$, and $800^{\circ} \mathrm{C}$.
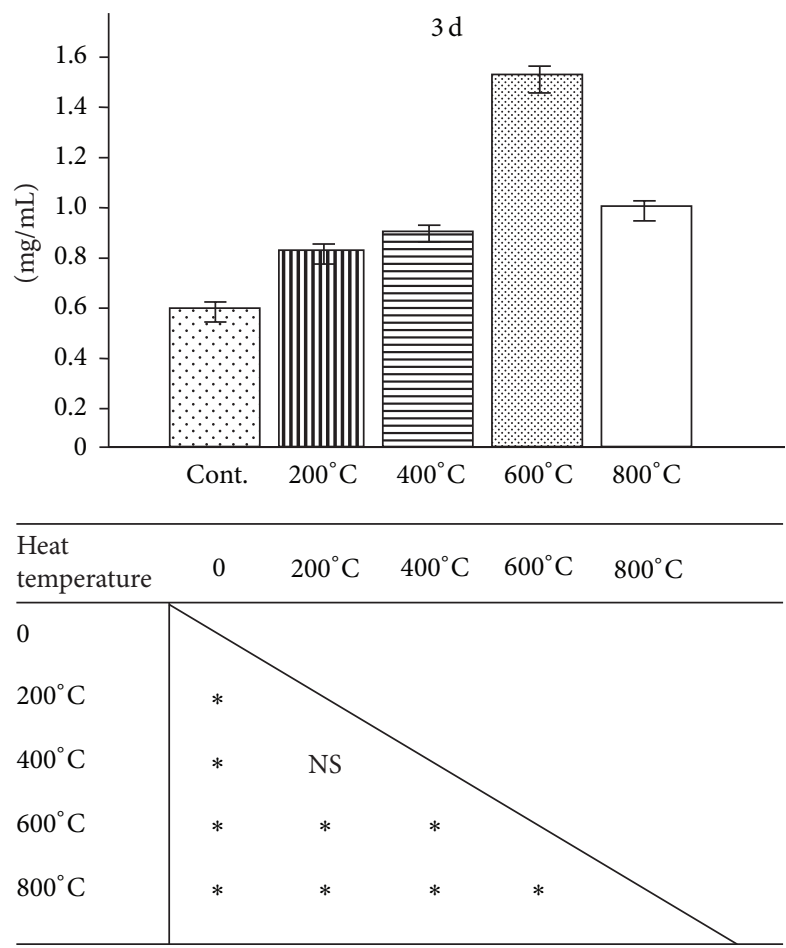

${ }^{*} P<0.05$, NS: not significant

FIgURE 9: Runx2 mRNA on the surfaces of Ti6Al4V specimens subjected to alkali treatment $(\mathrm{A} 30)$ and alkali-heat $(\mathrm{AH})$ treatments with the subsequent heating temperatures at $200^{\circ} \mathrm{C}, 400^{\circ} \mathrm{C}, 600^{\circ} \mathrm{C}$, and $800^{\circ} \mathrm{C}$. substrate, indicating that the surface layer is mechanically weak. Consequently, combined alkali and heat treatments have proven to produce a more stable alkali titanate layer in recent research.

From the surface characterizations results, alkali treatments with $10 \mathrm{M} \mathrm{NaOH}$ solution at $30^{\circ} \mathrm{C}$ provided a fine nanoporous network. This study proposed that the pore size of the porous network was sensitive to the concentration of alkali solution. The mechanism of the formation of a porous network on Ti metal or its alloys during alkali treatment is the corrosive attack of the hydroxyl groups [14]. The formation of a nanoporous structure can be attributed to the higher concentration of $10 \mathrm{M} \mathrm{NaOH}$, which provides more hydroxyl groups to incorporate into the metal surface and induce the formation of more pores.

In XPS analysis, the results confirm that the surface chemistry of the alkali-treated alloy did not include $\mathrm{Al}$ and $\mathrm{V}$ before and after heat treatments until $600^{\circ} \mathrm{C}$. It has been demonstrated that the alloy species of $\mathrm{Al}$ and $\mathrm{V}$ selectively dissolve in the alkaline solution, and $\mathrm{Al}$ and $\mathrm{V}$ oxides are formed in the $\mathrm{TiO}_{2}$ layer after heat treatment, which contribute to eliminating the toxicity of the Ti6Al4V alloy $[15,16]$. Furthermore, Kobayashi et al. found that a graded surface consisting of a sodium titanate layer, sodium titanate dense film, $\mathrm{TiO}_{2}$ layer, and alloy substrate was formed during the heat treatment at $600^{\circ} \mathrm{C}$ in 2005 [16]. Considering the reappearance of $\mathrm{Al}$ and $\mathrm{V}$ in the sodium titanium layer after heat treatment at $800^{\circ} \mathrm{C}$, some researchers reported that the binding energies of $\mathrm{Al}$ and $\mathrm{V}$ in their oxides decreased after 
heat treatment, which could lead to easier detection after treatment at high temperatures $[17,18]$.

The XRD findings were in agreement with the results of conventional alkali-heat treatment and showed that the sodium hydrogen titanate was gradually transformed into amorphous sodium titanate and/or crystalline sodium titanate after the heat treatments. When the $\mathrm{NaOH}$-treated Ti metal is subjected to a heat treatment, its surface sodium titanite hydrogel layer is dehydrated and transformed into an amorphous sodium titanate at 400 to $500^{\circ} \mathrm{C}$, fairly deified at $600^{\circ} \mathrm{C}$, and then converted into crystalline sodium titanate and rutile above $800^{\circ} \mathrm{C}$ [19]. The results of this study clearly showed that heat treatment at $600^{\circ} \mathrm{C}$ was the most favorable for the formation of amorphous sodium titanate, which has also been selected for the heating temperature in alkali and heat treatment technique for clinical applications.

In this study, albumin and cell proliferation of BMMSCs, Runx2 expression, ALP activity, OCN production, and Ca deposition were performed to demonstrate the biocompatibility of the modified Ti6Al4V alloy surface, which is considered as a critical prerequisite for cell proliferation and differentiation. The adsorption of ECM adhesive proteins onto implanted materials is the first essential step in bone tissue response and affects cell adhesion and proliferation [20]. BMMSCs were used to model osteoinduction and osteoblastic differentiation in cell culture performed on different titanium substrates. Adhesion and osteoblastic differentiation under culture conditions, including osteogenic supplements, occurred to a varying degree on the different surfaces [21]. Initial cell adhesion is the key step in the ensuing cell proliferation and differentiation on biomaterials [19]. Three stages can be distinguished in osteogenic differentiation: proliferation, matrix development/maturation, and mineralization [22]. Runx2 is an important transcription factor necessary for osteoblast differentiation and is expressed in the early stages of osteogenic differentiation. A previous study has found that the initial adhesion force of osteoblasts increased on Ti6Al4V alloy subjected to high temperature surface treatment [23]. The differentiation behaviors of osteoblasts on the surface of alkali-heat treated titanium-8tantalum-3niobium alloy were accelerated compared with that of the sample without heat treatment [24]. Cell attachment is a complicated process that involves several surface features, such as topographic morphology, surface roughness, surface chemistry, and phase state. Here, we claim the importance of the surface phase for cell adhesion. The results showed that there were no significant changes in the nanostructure, roughness, and chemical compositions of the samples before and after heat treatments $\left(200-600^{\circ} \mathrm{C}\right)$, but there are changes in the phases. The amount of amorphous sodium titanate is the key factor for enhancing cell adhesion. Our experiment is the first to provide evidence that BMMSCs exhibit a trend of adhesion on nanoporous structures with an amorphous sodium titanate phase depending on the temperature of prior heat treatments. As the temperature of heat treatment increased to $800^{\circ} \mathrm{C}$, in addition to the transformation to the crystalline sodium titanate and appearance of the toxic elements $\mathrm{Al}, \mathrm{V}$, the distortion of the nanoporous structure and the change of the nanoscale surface roughness have an adverse effect on the cell adhesion. Cell adhesion is sensitive to the contribution of the nanotopography to the mimicry of the cellular environments to favor the process of rapid bone accrual. For example, the structure of the epithelial basement membrane contains pores of approximately $70-100 \mathrm{~nm}$ [25]. In this study, the pore size of 50-100 $\mathrm{nm}$ of the nanopores obtained by alkaliheat treatment $\left(200-600^{\circ} \mathrm{C}\right)$ was approximating to that of the basement membranes. Furthermore, the nanoscale surface roughness was also maintained at about $R_{a}=20 \mathrm{~nm}$ even after heat treatment $\left(200-600^{\circ} \mathrm{C}\right)$, in the optimum surface roughness range $R_{a}=10-45 \mathrm{~nm}$, which promoted four types of cell adhesion in previous work [26]. Numerous studies have shown the ALP activation effect of surface-modified materials [27] and our results support these conclusions. Furthermore, the observed increase of OCN production in the presence of the nanostructured surfaces is also in agreement with previous findings [28]. It is believed that the chemical bonding between the alkali- and heat-treated titanium alloy metal surface and the bone surface, via the apatite layer, plays a major role in bone-bonding behavior. Alkali- and heat-treated titanium implants have a thin reactive layer on their surface as a result of the alkali and heat treatments. This layer can form apatite in SBF, like bioactive glasses and glass ceramics, which is also thought to occur in vivo. Apatite formation on the surface of the material is considered a prerequisite for direct bone-bonding. Details of the underlying mechanism of apatite formation on the surface of alkali- and heat-treated titanium metals have been described by Kim et al. [8]. Osteogenic cells may attach to the surface of alkali- and heat-treated titanium alloy implant themselves or to the apatite formed on the surface, and this may enhance growth and differentiation [28]. Thus, the gap initially created between the bone and the implant following the implantation procedure may be filled with new bone faster with alkali- and heat-treated implants than with untreated implants. Once new bone forms, tight bonding between the bone and the alkali- and heat-treated titanium implant develops via the biological apatite in the bone and the bone-like apatite on the surface of the implant. This might explain the strong bonding between the bone and the alkaliand heat-treated titanium implants.

\section{Conclusion}

Surface characterization studies revealed that the nanotopography, surface chemistry, and surface roughness of the modified layer obtained by alkali treatment were maintained even after heat treatments at 200,400 , and $600^{\circ} \mathrm{C}$. Only the phase structure was altered, particularly the amorphous sodium titanate phase, which might play a crucial role in promoting cell adhesion on the nanoporous surface with the increase in heating temperatures. The heat treatment of $800^{\circ} \mathrm{C}$ transformed the nanoporous structure into a crystalline structure at the macroscale level with the reappearance of $\mathrm{Al}$ and $\mathrm{V}$, which induced a decline in cell attachment. Consequently, these results suggest that nanoporous surface features and BMMSCs cell proliferation and bone differentiation on Ti6Al4V surface may be controlled and improved by varying the temperature of the initial alkali immersion and 
subsequent heat treatment. The materials should be further studied as a novel bioactive material for dental implants. Further development of advanced implant materials using nanotechnology should further improve their osseointegration.

\section{Conflict of Interests}

The authors declare that there is no conflict of interests regarding the publication of this paper.

\section{Acknowledgments}

This work was supported by Grant-in Aid for Scientific Research (26861664) from the Japan Society for the Promotion of Science. The authors would like to thank Mr. H. Hori, Central Institute of Dental Research, Osaka Dental University, Japan, for his help with experimental techniques.

\section{References}

[1] M. Vandrovcová and L. Bačáková, "Adhesion, growth and differentiation of osteoblasts on surface-modified materials developed for bone implants," Physiological Research, vol. 60, no. 3, pp. 403-417, 2011.

[2] B. D. Boyan, T. W. Hummert, D. D. Dean, and Z. Schwartz, "Role of material surfaces in regulating bone and cartilage cell response," Biomaterials, vol. 17, no. 2, pp. 137-146, 1996.

[3] Z. Schwartz, C. H. Lohmann, J. Oefinger, L. F. Bonewald, D. D. Dean, and B. D. Boyan, "Implant surface characteristics modulate differentiation behavior of cells in the osteoblastic lineage," Advances in Dental Research, vol. 13, pp. 38-48, 1999.

[4] K. Takeuchi, L. Saruwatari, H. K. Nakamura, J.-M. Yang, and T. Ogawa, "Enhanced intrinsic biomechanical properties of osteoblastic mineralized tissue on roughened titanium surface," Journal of Biomedical Materials Research Part A, vol. 72, no. 3, pp. 296-305, 2005.

[5] S. Komasa, Y. Taguchi, H. Nishida, M. Tanaka, and T. Kawazoe, "Bioactivity of nanostructure on titanium surface modified by chemical processing at room temperature," Journal of Prosthodontic Research, vol. 56, no. 3, pp. 170-177, 2012.

[6] S. Komasa, T. Kusumoto, Y. Taguchi et al., "Effect of nanosheet surface structure of titanium alloys on cell differentiation," Journal of Nanomaterials, vol. 2014, Article ID 642527, 11 pages, 2014.

[7] H. Xing, S. Komasa, Y. Taguchi, T. Sekino, and J. Okazaki, "Osteogenic activity of titanium surfaces with nanonetwork structures," International Journal of Nanomedicine, vol. 9, no. 1, pp. 1741-1755, 2014.

[8] H. M. Kim, F. Miyaji, T. Kokubo, and T. Nakamura, "Effect of heat treatment on apatite-forming ability of Ti metal induced by alkali treatment," Journal of Materials Science: Materials in Medicine, vol. 8, no. 6, pp. 341-347, 1997.

[9] K. Nishio, M. Neo, H. Akiyama et al., "The effect of alkali- and heat-treated titanium and apatite-formed titanium on osteoblastic differentiation of bone marrow cells," Journal of Biomedical Materials Research, vol. 52, no. 4, pp. 652-661, 2000.

[10] S. Nishiguchi, S. Fujibayashi, H.-M. Kim, T. Kokubo, and T. Nakamura, "Biology of alkali- and heat-treated titanium implants," Journal of Biomedical Materials Research Part A, vol. 67, no. 1, pp. 26-35, 2003.
[11] S. Nishiguchi, H. Kato, H. Fujita et al., "Titanium metals form direct bonding to bone after alkali and heat treatments," Biomaterials, vol. 22, no. 18, pp. 2525-2533, 2001.

[12] T. Fujino, Y. Taguchi, S. Komasa, T. Sekino, and M. Tanaka, "Cell differentiation on nanoscale features of a titanium surface: effects of deposition time in $\mathrm{NaOH}$ solution," Journal of Hard Tissue Biology, vol. 23, no. 1, pp. 63-69, 2014.

[13] H.-M. Kim, F. Miyaji, T. Kokubo, and T. Nakamura, "Preparation of bioactive Ti and its alloys via simple chemical surface treatment," Journal of Biomedical Materials Research, vol. 32, no. 3, pp. 409-417, 1996.

[14] S. Yamaguchi, H. Takadama, T. Matsushita, T. Nakamura, and T. Kokubo, "Cross-sectional analysis of the surface ceramic layer developed on $\mathrm{Ti}$ metal by $\mathrm{NaOH}$-heat treatment and soaking in SBF," Journal of the Ceramic Society of Japan, vol. 117, no. 1370, pp. 1126-1130, 2009.

[15] H.-M. Kim, H. Takadama, F. Miyaji, T. Kokubo, S. Nishiguchi, and T. Nakamura, "Formation of bioactive functionally graded structure on Ti-6Al-4V alloy by chemical surface treatment," Journal of Materials Science: Materials in Medicine, vol. 11, no. 9, pp. 555-559, 2000.

[16] S. Kobayashi, T. Inoue, and K. Nakai, "Effect of heat treatment on cohesion of films on alkali-treated titanium," Materials Transactions, vol. 46, no. 2, pp. 207-210, 2005.

[17] J. H. Park, D. Y. Lee, and K. N. Kim, Characterization of the Surface Oxide on Thermally Oxidized Ti6Al4V Alloy for Improvement of Bioactivity, Abs. 1, 205th Meeting, The Electrochemical Society, Pennington, NJ, USA, 2004.

[18] L. Saldaña, N. Vilaboa, G. Vallés, J. González-Cabrero, and L. Munuera, "Osteoblast response to thermally oxidized Ti6Al4V alloy," Journal of Biomedical Materials Research Part A, vol. 73, no. 1, pp. 97-107, 2005.

[19] H. Zhang, K. Bremmell, S. Kumar, and R. S. C. Smart, "Vitronectin adsorption on surfaces visualized by tapping mode atomic force microscopy," Journal of Biomedical Materials Research-Part A, vol. 68, no. 3, pp. 479-488, 2004.

[20] G. Mendonça, D. B. S. Mendonça, F. J. L. Aragão, and L. F. Cooper, "The combination of micron and nanotopography by $\mathrm{H}_{2} \mathrm{SO}_{4} / \mathrm{H}_{2} \mathrm{O}_{2}$ treatment and its effects on osteoblast-specific gene expression of hMSCs," Journal of Biomedical Materials Research A, vol. 94, no. 1, pp. 169-179, 2010.

[21] K. Anselme, "Osteoblast adhesion on biomaterials," Biomaterials, vol. 21, no. 7, pp. 667-681, 2000.

[22] C. C. Wang, Y. C. Hsu, M. C. Hsieh, S. P. Yang, F. C. Su, and T. M. Lee, "Effects of nano-surface properties on initial osteoblast adhesion and $\mathrm{Ca} / \mathrm{P}$ adsorption ability for titanium alloys," Nanotechnology, vol. 19, no. 33, Article ID 335709, 2008.

[23] B.-A. Lee, C.-H. Kang, M.-S. Vang et al., "Surface characteristics and osteoblastic cell response of alkali-and heat-treated titanium-8tantalum-3niobium alloy," Journal of Periodontal and Implant Science, vol. 42, no. 6, pp. 248-255, 2012.

[24] G. Mendonça, D. B. S. Mendonça, F. J. L. Aragão, and L. F. Cooper, "Advancing dental implant surface technology-from micron-to nanotopography," Biomaterials, vol. 29, no. 28, pp. 3822-3835, 2008.

[25] F. Gentile, L. Tirinato, E. Battista et al., "Cells preferentially grow on rough substrates," Biomaterials, vol. 31, no. 28, pp. 7205-7212, 2010.

[26] B. Bell, M. Schuler, S. Tosatti, M. Textor, Z. Schwartz, and B. Boyan, "Osteoblast response to titanium surfaces functionalized with extracellular matrix peptide biomimetics," Clinical Oral Implants Research, vol. 22, pp. 865-872, 2011. 
[27] F. Iwasa, "Micro-nano-hybrid surface to alleviate biological aging of UV-photofunctionalized titanium," International Journal of Nanomedicine, vol. 6, pp. 1327-1341, 2011.

[28] P. Li and K. De Groot, "Calcium phosphate formation within sol-gel prepared titania in vitro and in vivo," Journal of Biomedical Materials Research, vol. 27, no. 12, pp. 1495-1500, 1993. 

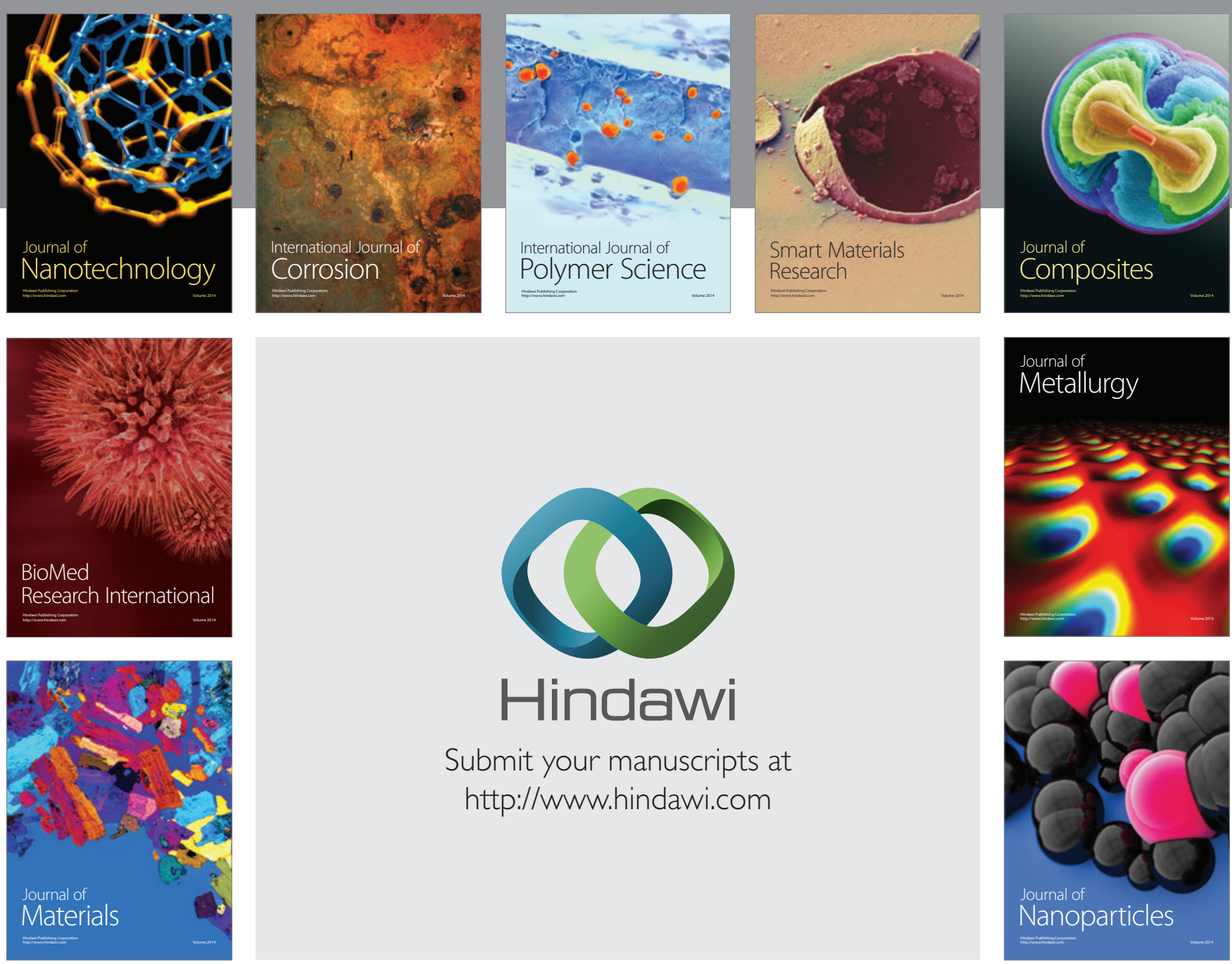

Submit your manuscripts at http://www.hindawi.com
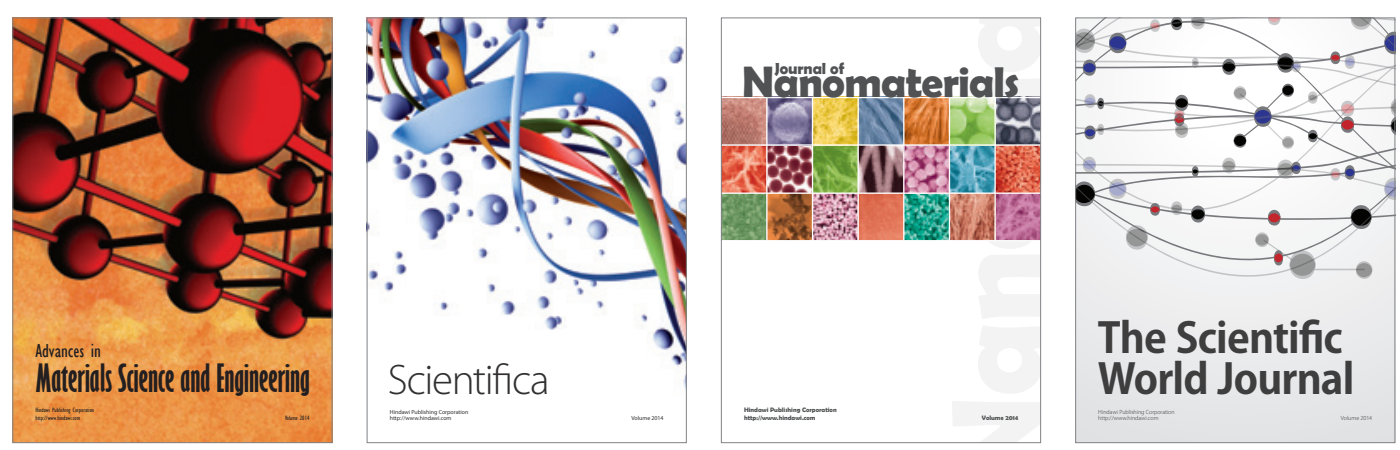

\section{The Scientific World Journal}
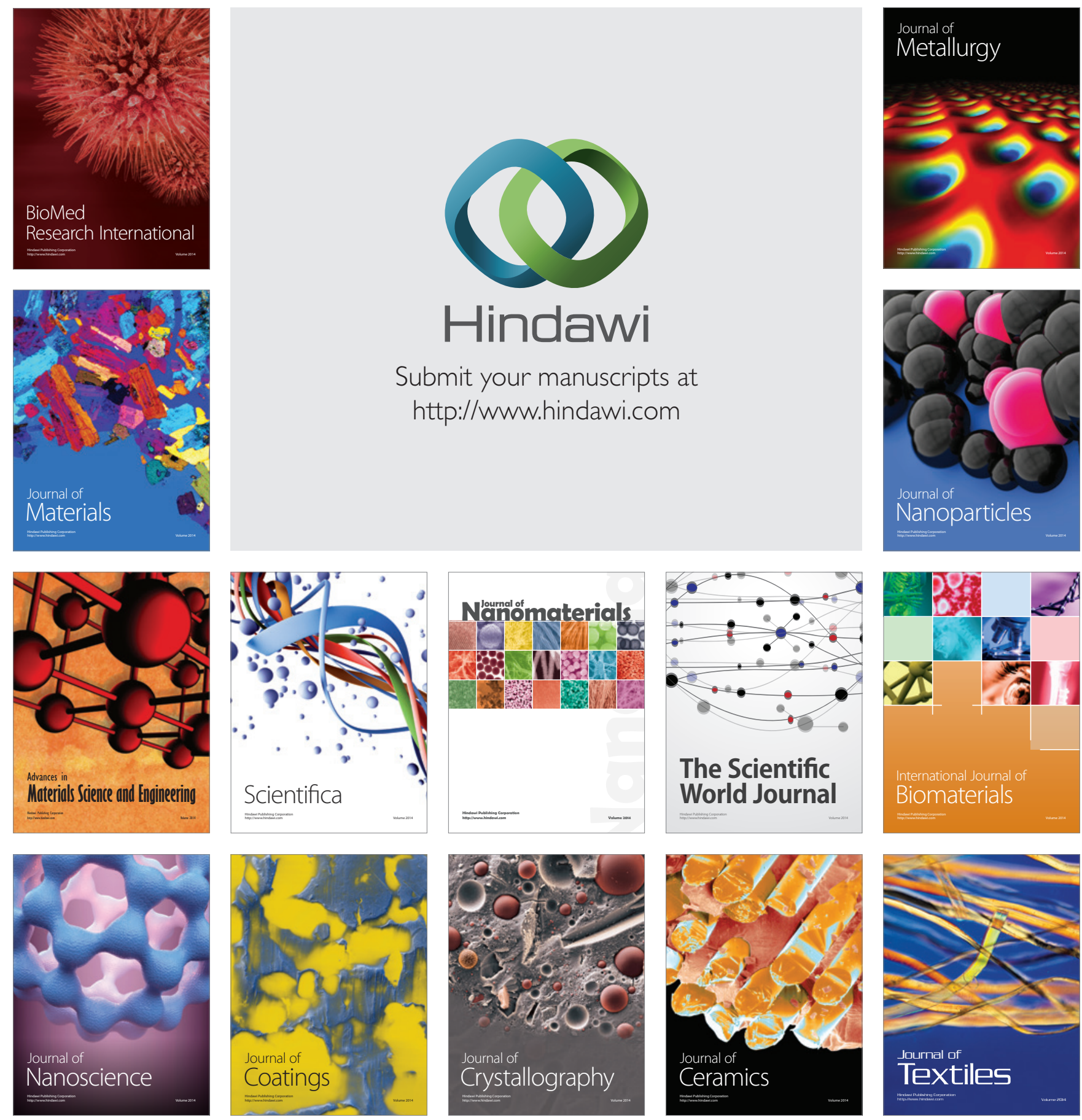